\title{
Optimizing Societal Benefit using a Systems Engineering Approach for Implementation of the GEOSS Space Segment
}

\author{
Brian D. Killough, Jr. , Stephen P. Sandford ${ }^{\mathrm{a}}$, L. DeWayne Cecil ${ }^{\mathrm{b}}$, Shelley Stover ${ }^{\mathrm{a}}$, Kim Keith ${ }^{\mathrm{a}}$ \\ a NASA Langley Research Center (LaRC), Hampton, VA, USA, 23681 \\ b.S. Geological Survey (USGS), Idaho Falls, ID, USA, 83402
}

\begin{abstract}
The Group on Earth Observations (GEO) is driving a paradigm shift in the Earth Observation community, refocusing Earth observing systems on GEO Societal Benefit Areas (SBA). Over the short history of space-based Earth observing systems most decisions have been made based on improving our scientific understanding of the Earth with the implicit assumption that this would serve society well in the long run. The space agencies responsible for developing the satellites used for global Earth observations are typically science driven. The innovation of GEO is the call for investments by space agencies to be driven by global societal needs. This paper presents the preliminary findings of an analysis focused on the observational requirements of the GEO Energy SBA. The analysis was performed by the Committee on Earth Observation Satellites (CEOS) Systems Engineering Office (SEO) which is responsible for facilitating the development of implementation plans that have the maximum potential for success while optimizing the benefit to society. The analysis utilizes a new taxonomy for organizing requirements, assesses the current gaps in spacebased measurements and missions, assesses the impact of the current and planned space-based missions, and presents a set of recommendations.
\end{abstract}

Keywords: CEOS, GEO, GEOSS, SBA, Societal Benefit Area, Systems Engineering, Energy

\section{INTRODUCTION}

The Group on Earth Observations is driving a paradigm shift in the Earth Observation community, refocusing Earth observing systems on their societal benefit. Over the short history of Earth observing systems most decisions have been made based on improving our scientific understanding of the Earth with the implicit assumption that this would serve society well in the long run. The various space agencies responsible for developing the satellites used for global Earth observations, if not the operational agencies, have been science driven. The innovation of GEO is the call for investments by space agencies to be society driven.

Time and measurement gaps in space observations and the unnecessary duplication of measurements provide evidence that the world's space agencies do not have a unified strategy for collecting critical space-based observations. This complex multi-variable problem is ripe for a systems engineering solution. The preliminary findings in this paper suggest an optimized systems engineering solution is not only possible, but necessary to sufficiently and effectively address the implementation of the Global Earth Observation System of Systems (GEOSS) space segment.

The preliminary findings of this GEO Societal Benefit analysis focused on the observational requirements of the Energy SBA are presented. The analysis was performed by the CEOS SEO which is responsible for facilitating the development of implementation plans that have the maximum potential for success while optimizing the benefit to society. The analysis utilizes a new taxonomy for organizing requirements, assesses the current gaps in space-based measurements and missions, assesses the SBA impact of the current and planned space-based missions, and presents a recommended path for the future. 


\subsection{Committee on Earth Observations Satellites (CEOS)}

CEOS endeavors to coordinate satellite missions worldwide and maximize the use of satellite data to provide a detailed and accurate view of the Earth system. Established in 1984, CEOS provides a broad framework for international coordination of space-based Earth observation missions through the cooperation of its 48 member agencies and associates. By working together, CEOS members advance the coordination of current Earth observing systems and the development of future systems that will not only fill observational gaps, but will possess new capabilities designed to answer fundamental questions about the Earth system.

To design and implement the space segment requires close coordination with ground and suborbital system designers as well as a clear understanding of the GEOSS space segment requirements. Understanding these requirements demands that CEOS work closely with GEO officials through a process of trade studies and negotiations with users of GEOSS products to ensure the final design is useful and practicable within the resources available. Given that the GEO and the GEOSS are organized around SBAs and given that the space agencies of CEOS traditionally organize around systems that observe specific parts of the Earth system, it is important to determine the best path for CEOS to follow to develop the space segment of the GEOSS.

In recent years, CEOS has refined its focus to directly implement the work and goals of the GEO. In 2005, the CEOS membership decided to realign its strategies and plans to deliver the space-based component of GEOSS. As one of the original contributing organizations of GEO, CEOS fostered space agency participation in the initial GEO 2006 work plan and contributed to tasks that directly addressed or cut across all nine GEOSS SBAs including Agriculture, Biodiversity, Climate, Disasters, Ecosystems, Energy, Health, Water, and Weather. CEOS' involvement continues at a similar level for the current GEO work plan.

CEOS also works closely with Global Climate Observing System (GCOS) leaders. In 2006, CEOS provided a coordinated response on behalf of its member space agencies to the proposed requirements for the space-based component of the GCOS Implementation Plan. The CEOS response was a comprehensive collection of actions aimed at fulfilling climate observing needs in the atmosphere, ocean, and terrestrial domains, as well as a number of cross-cutting areas. CEOS provided the opportunity for space agencies to review the way in which multi-agency climate observations are prioritized, agreed, funded, implemented, and monitored. CEOS also identified what can be achieved by better coordination of existing and future capabilities as well as specific improvements that require additional resources or mandates beyond the present capacity of member space agencies.

\subsection{CEOS Systems Engineering Office (SEO)}

The CEOS Systems Engineering Office (SEO) was established in April 2007 at the NASA Langley Research Center to facilitate the development of CEOS space constellation plans. The SEO provides systems engineering leadership, provides a framework for a coherent science and engineering plan, and provides decision support tools for trade studies and the assessment of execution options to maximize the probability of their implementation. To date, the SEO technical efforts include requirements definition, constellation assessment, gap analyses, and future space implementation planning. In addition, the SEO fosters communications among CEOS partners by coordinating and participating in CEOS Constellation Workshops and Working Group meetings, developing tools for file sharing and action item tracking, developing visualization products for educating the global Earth Observation community about CEOS, and supporting the content development and management of the CEOS website. 


\subsection{GEOSS Systems Engineering Framework}

The purpose of the CEOS is to promote coordination between member organizations and cooperation in the development of Earth observing satellites for GEOSS. The advantages of coordination include ensuring the plans are comprehensive and that the important tasks are done within the resources available such that the global program is useful and practicable. However, the member organizations agree only to make their best effort to cooperate and to promote cooperation. No binding funding or time commitments are made. The member organizations are free agents primarily accountable to their national stakeholders.

So the question arises, "How is coordination among free agents encouraged, facilitated and accomplished?" Since CEOS exists and has active participation by its members it can safely be assumed that each member organization perceives some benefit to itself from cooperating with the other members to develop Earth observing systems. With this motivation assumed, the next part of the answer lies in the methods used. There are three important methods to employ for achieving the space segment of GEOSS.

One is to encourage and facilitate the development of further agreements between parties that are more specific and binding than those contained in the CEOS charter and that more strongly commit cooperative resources to achieve certain Earth observing goals. This is sometimes the only method utilized and is effective but works one mission at a time and not in the context of a system.

A second method is to identify the principles of operations that nurture cooperative relationships that should guide the independent organizations in order that they may achieve the advantages of the cooperation. GCOS developed such a set of principles for achieving climate objectives through cooperation. Once identified and agreed upon, obtaining widespread cooperation by member organizations to abide by these same principles is a separate challenge.

A third yet unutilized method to achieve the purpose of CEOS is to provide a new organizational construct or "taxonomy" of a global earth observing system that assumes and depends upon the advantages of coordination and cooperation among the member organizations. Such a "taxonomy" describes a global satellite system that achieves certain specified goals that the collective member organizations agree are important. These goals are described in the GEOSS 10-year Implementation Plan. A systems engineering "taxonomy" is powerful in achieving coordination because it provides to the member organizations a reference to guide their decisions and to measure their contributions to achieving the collective goals. It further allows the determination of the minimum set of global resources required to achieve the stated goals. Because the "taxonomy" is designed assuming coordination and cooperation to the extent it is implemented, it automatically achieves all the technical and resource advantages promised by the CEOS charter.

This third method for encouraging, facilitating and accomplishing coordination and cooperation provides an important and unique advantage. The advantages of coordination and cooperation are not often described explicitly, but the pithy statement of Aristotle, which captures the guiding principle of systems thinking, is the most concise way of describing these advantages: "The whole is greater than the sum of the parts". For CEOS purposes, "the parts" are the programs implemented by the free agent member organizations. "The sum of the parts" is what gets built with no coordination among programs. "The whole" might be described by the taxonomy mentioned above. For a given set of member organizations and their resources, acting in concert will deliver more value from Earth observations than acting alone. Taking a global system approach with the taxonomy can help to ensure that nothing important is missed and that the most important tasks are accomplished utilizing the resources available. This organizational plan reveals the potential benefits of coordination and cooperation at the global systems level, beyond the mission/measurement level. Without a commonly accepted description of a global satellite system where the whole is greater than the sum of the parts, progress towards the goals of CEOS and GEO will be slow and intermittent. Put as simply as possible, "Without a clear description of where we want to be, how can we ever get there”? 
This description or "taxonomy" of a global satellite system requires no formal commitment by the member organizations to be effective. Because the advantages of coordination and cooperation are so strong, the development of the "taxonomy" by the international community (CEOS) and its existence as a point of reference (a guide and a measure) to the individual member organizations alone are enough to dramatically accelerate the achievement of coordination and cooperation in the development of the GEOSS.

The powerful innovation of the GEO is to strongly connect Earth observations to societal benefits. This makes it necessary to link all satellite observations to societal benefits. Once this premise is accepted it is possible to begin to utilize systems thinking to enable the CEOS goals. Everyone who has had the responsibility to convert a complex idea into a physical system understands the critical importance of defining the purpose of the system, producing a qualitative functional model of the system, defining requirements for all parts of the system clearly linked to the purpose of the system and of being able to describe the final appearance of the system to anyone participating in its realization.

Coordination and cooperation can be accelerated by providing a description of a global satellite system that depends upon coordination and cooperation to be realized. In order to describe a global satellite system where the whole is greater than the sum of its parts requires an understanding of the larger system into which the satellite system fits. It is generally agreed that the GEOSS is that larger system and the GEOSS 10-year Implementation Plan (IP) Reference Document ${ }^{1}$ serves as the source of requirements for the global satellite system. Each SBA chapter in this document provides a table of "Observational Requirements". Such a source of requirements is absolutely essential in order to achieve the goals of the CEOS. However, to be helpful, these requirements must reflect a useful model of the final system to be realized. Although the GEOSS IP contains a table called "Observational Requirements", the table in fact contains items that are not observations. In order for these tables to be most helpful for CEOS they need to reflect the requirements for the GEOSS as a whole and not just the observations or measurements that need to be collected. For this reason the following system model is proposed. Its purpose is to represent what is needed functionally to achieve the societal benefits for which GEO strives.

\subsection{GEOSS Taxonomy Summary}

This simple, generalized taxonomy model assumes that benefits to society are achieved when information is provided to members of society that helps them make better decisions prior to taking actions. Decision makers include government officials (from national to local), policymakers, lawmakers, organizational leaders (from corporate to volunteer) and individual citizens. This actionable information is provided through information products \& services that vary in form depending on the decision maker. Rarely is actionable information delivered successfully where there is any indication of the infrastructure that produced the information. For example, many people have no idea that their daily weather forecast flows from satellite measurements, computer models and knowledge obtained through decades of scientific study. Thus, users typically fail to understand the investment required for the benefits they depend upon. Accuracy and minimal uncertainty in information products and services can be the result of improved knowledge of the Earth system and its manifestation in predictive and descriptive models used to generate information products and services. Observations are collected and analyzed to provide data that serve as direct information for a decision maker and/or as input to predictive models, and/or as the basis for improved understanding. It is these observations and data that are the result of technologically advanced space instruments and missions developed by the CEOS space agencies.

This model of the functional flow from missions and measurements to societal benefits is proposed as the basis for organizing the global satellite system requirements and providing their context. The taxonomy that reflects this model is presented below with specific categories for decision makers, informational products and services, science knowledge and models, measurements, instruments and missions. 


\subsection{GEOSS Taxonomy Definition}

To provide a systematic framework, the SEO proposes a taxonomy (Figure 1) that captures the new thinking of the GEO, is understandable to all contributors to the GEOSS, is comprehensive in scope, and will facilitate communications and actions toward implementation. This framework allows the definition and traceability of requirements and the assessment of gaps or impacts at every level to enable CEOS member organizations and CEOS organizational groups to increase coordination and collaboration toward the realization of a GEOSS. The proposed framework links the key decisions in each GEO SBAs to their required informational products, science models, space missions, instruments and measurements.

\subsubsection{Decision Topics}

Decision topics are questions or topic areas considered by individual or group decision-makers within societal benefit areas. These decision topics require the use of informational data products to support decision making and to take action for societal benefit. Examples of decisionmakers include local and national governmental officials, policymakers, lawmakers, organizational and business leaders, and the general public.

\subsubsection{Information Products and Services}

Information products and services provide direct benefit to society as articulated in GEOSS Implementation Plan ${ }^{1}$ for each SBA. These products are developed by combining Measurements, Science Knowledge and Models of the Earth system and other data to provide decision makers the ability to choose a course of action. Some examples include forecasts, assessments, and reports.

\subsubsection{Science Knowledge and Models}

Science Knowledge and Models are the understanding of geophysical processes and interactions representing geophysical parameter behavior or future geophysical states. This includes data products from retrieved environmental variables which have been spatially and/or temporally resampled or model output from analyses based on measurements. Some examples include global maps, long-term trend data, and modeled parameters.

\subsubsection{Measurements}

Measurements are direct observations of specific geophysical parameters. These correspond to corrected and calibrated data or retrieved environmental variables. Some examples include radiance, ocean height, soil moisture, relative humidity.

\subsubsection{Instruments and Missions}

Instruments and Missions are the implementation method for making space-based measurements typically accomplished by world space agencies under strict technical and cost constraints.

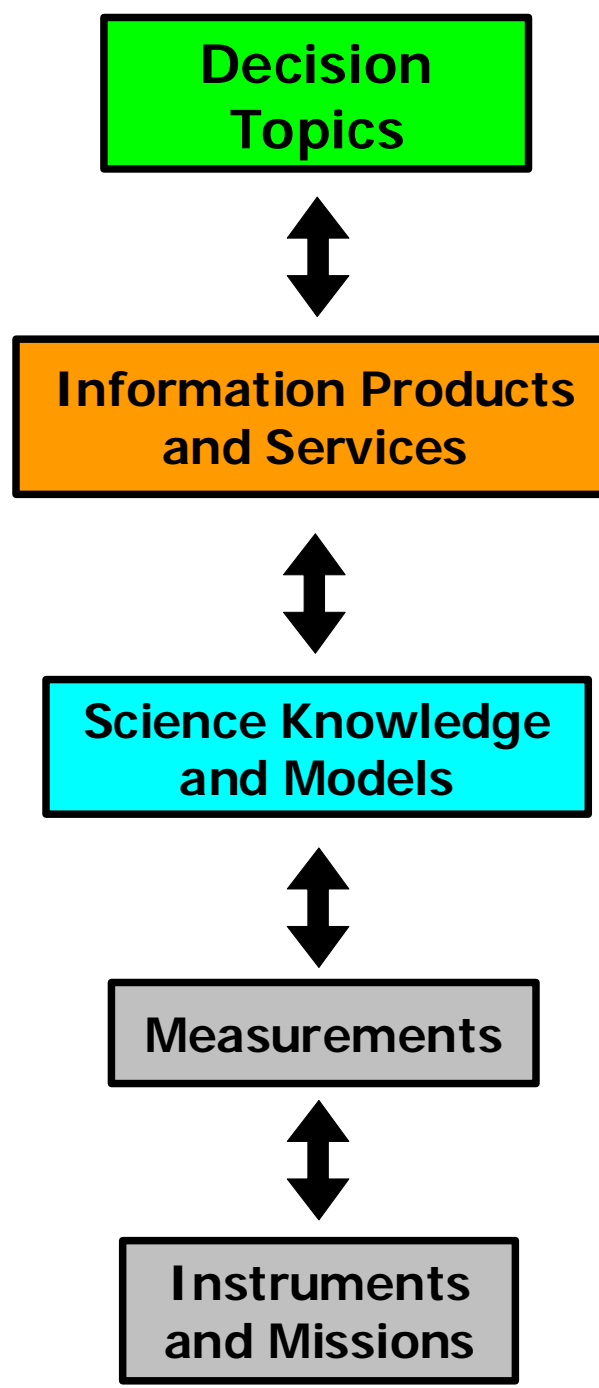

Figure 1. Proposed GEOSS Systems Engineering Framework (taxonomy) 


\subsection{Energy SBA Example}

The proposed systems engineering process and organizational taxonomy was used to analyze a single decision topic within the GEOSS Energy SBA, "Identify and quantify the availability of traditional and renewable energy resources". This particular topic is one of the highest priority decision topics within the Energy SBA. Other decision topics include: Environmental impacts of energy resource exploration, extraction, and exploitation; Energy production impact on global climate change; Long-term climate impact on energy resource supply and demand; Weather impact on energy resource supply and demand; and Space Weather impacts on energy transmission systems.

Measurement, Instrument and Mission data were obtained from the recently updated Earth Observation (EO) Handbook (2008 draft) and the SEO Systems Engineering Database. Both of these data resources are rather new and require CEOS validation to eliminate errors and improve accuracy. For this reason, the data contained in this preliminary analysis should be considered "qualitative" in nature and lead to further more detailed analyses to reach any significant "quantitative" conclusions or recommendations. Content for informational products and services and science knowledge and models were obtained from Richard Eckman ${ }^{2,3}$ (NASA Langley Research Center, CEOS Energy SBA Lead) and from extensive web searches.

\subsection{Energy SBA Requirements}

Figure 2 summarizes a single Energy SBA decision topic and the types of information products and services, types of science knowledge and models, and types of measurements required to support this decision topic. This set of data was used as a guide to evaluate the impact of potential measurement gaps, which is presented in Section 4.0.

Taxonomy

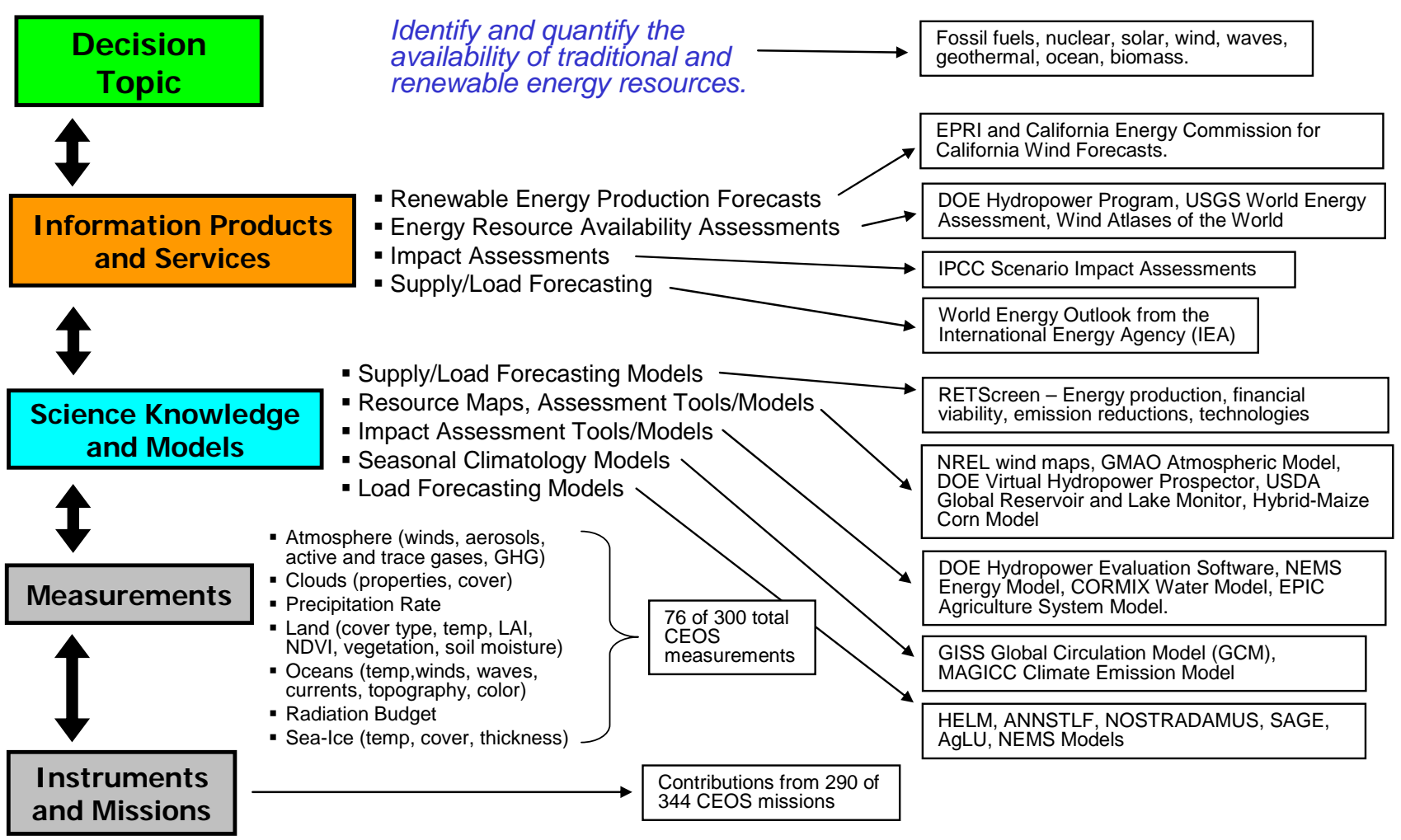

\section{Examples}

\section{Categories}

Identify and quantify the availability of traditional and renewable energy resources.

EPRI and California Energy Commission for California Wind Forecasts.

- Renewable Energy Production Forecasts

Energy Resource Availability Assessments

- Impact Assessments

- Supply/Load Forecasting

Ass 


\subsection{Energy SBA Gap Assessment}

The following tables summarize the total number of CEOS space missions (current and planned) over the next 20 years relevant to the Energy SBA decision topic presented in Section 3.0. Table 1 presents data for atmospheric parameters and Table 2 presents data for ocean and land parameters.

\begin{tabular}{|c|c|c|c|c|c|c|c|c|c|c|c|c|c|c|c|c|c|c|c|c|c|c|c|c|}
\hline Measurement I Year & Domain & ஃें & : & 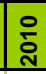 & न & & 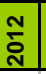 & 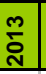 & त्रें & $\begin{array}{l}\text { مू } \\
\text { న్ }\end{array}$ & ลั. & & $\tilde{\sigma}$ & 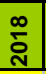 & 胥 & \begin{tabular}{|l|} 
స్ \\
\end{tabular} & స్ & \begin{tabular}{|l}
\multirow{N}{*}{} \\
Nat
\end{tabular} & $\begin{array}{l}\text { ָั } \\
\text { స్ }\end{array}$ & \begin{tabular}{|l|}
\multirow{2}{*}{} \\
W \\
\end{tabular} & 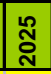 & $\begin{array}{l}\text { స్ } \\
\text { N. }\end{array}$ & & సิ \\
\hline Aerosol profile $\mathrm{HT}$ & tmosphere & 15 & 19 & 17 & 72 & 20 & 19 & 16 & 12 & 10 & & 6 & 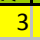 & 5 & 5 & 6 & 3 & 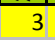 & 2 & 2 & 2 & . & & \\
\hline Aerosol profile LT & mosphere & 2 & 3 & 2 & 2 & 3 & 4 & 4 & 4 & 4 & & 3 & 2 & 2 & 2 & 2 & 0 & 0 & 0 & 0 & 0 & ( & & \\
\hline Air pressure over sea surface & tmosphere & 1 & 1 & 1 & 1 & 2 & 1 & 1 & 1 & 2 & & 2 & 1 & 1 & 1 & 1 & 0 & 0 & 0 & 0 & 0 & ( & & \\
\hline Atmospheric temp profile $\mathrm{HT}$ & tmosphere & 20 & 25 & 25 & & 4 & 20 & 18 & 16 & 14 & 1 & & 9 & 11 & 10 & 11 & 7 & 7 & 6 & 4 & 5 & 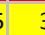 & 3 & \\
\hline Atmospheric temp profile LT & Atmosphere & 21 & 25 & 26 & 52 & 25 & 21 & 19 & 16 & 14 & 1 & & 9 & 11 & 9 & 10 & 6 & 6 & 5 & 4 & 5 & 3 & 3 & \\
\hline Atmospheric Temperature profile ( & Atmosphere & 9 & 9 & 10 & & 9 & 8 & 4 & 5 & 4 & & 4 & 2 & 2 & 1 & 1 & 0 & 0 & 0 & U & 0 & ( & 0 & \\
\hline Chemically active species: CO Total Column & Atmosphere & 2 & 2 & 1 & 1 & 3 & 2 & 3 & 3 & 4 & & 3 & 1 & 1 & 1 & 1 & 0 & 0 & 0 & 0 & 0 & ( & & \\
\hline Chemically active species: NO Total Column & Atmosphere & 2 & 1 & 1 & 1 & 1 & 0 & 0 & 0 & 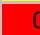 & & 0 & 0 & 0 & 0 & 0 & 0 & 0 & 0 & 0 & 0 & ( & & \\
\hline Chemically active species: NO2 Trop Column & here & 0 & 0 & $\mathrm{c}$ & 0 & 0 & 0 & 1 & 1 & 1 & & 1 & 0 & 0 & 0 & 0 & 0 & 0 & 0 & 0 & 0 & ( & & \\
\hline $\mathrm{SO} 2 \mathrm{Tc}$ & eere & 2 & 2 & 1 & 1 & 2 & 1 & 1 & 1 & 2 & & 2 & 1 & 1 & 1 & 1 & 0 & 0 & 0 & 0 & 0 & & & \\
\hline Cloud & here & 10 & 11 & 9 & 9 & 8 & 8 & 8 & 7 & $\epsilon$ & & 4 & 4 & 6 & 6 & 7 & 5 & 5 & 3 & 2 & 2 & & 1 & \\
\hline Cloud & ere & 29 & 36 & 34 & & 33 & 27 & 25 & 24 & 23 & 1 & 8 & 14 & 15 & 15 & 15 & 10 & 7 & 6 & 4 & 5 & & 4 & \\
\hline Cloud c & tere & 2 & 2 & 0 & & 0 & 0 & 0 & 0 & $\mathrm{c}$ & & 0 & 0 & 0 & 0 & 0 & 0 & 0 & 0 & 0 & 0 & & & \\
\hline Cloud & nere & 2 & 2 & 1 & 1 & 1 & 1 & 0 & 0 & $\mathrm{c}$ & & 0 & 0 & 0 & 0 & 0 & 0 & 0 & 0 & 0 & 0 & 0 & & \\
\hline Cloud & here & 23 & 27 & 25 & & 5 & 22 & 22 & 19 & 17 & & 4 & 11 & 12 & 13 & 13 & 9 & 7 & 6 & 4 & 5 & 3 & 3 & \\
\hline Cloud & here & 29 & 33 & 30 & & 9 & 26 & 23 & 22 & 22 & & 8 & 15 & 16 & 15 & 15 & 11 & 7 & 6 & 4 & 5 & & 4 & \\
\hline Cloud top temperature & Atmo & 22 & 25 & 23 & & 2 & 18 & 16 & 16 & 13 & 1 & 1 & 7 & 6 & 5 & 4 & 2 & 0 & 0 & n & 0 & & & \\
\hline Cloud type & there & 36 & 37 & 33 & & 2 & 28 & 24 & 22 & 23 & & 0 & 16 & 17 & 16 & 16 & 11 & 7 & 6 & 4 & 5 & 5 & 4 & \\
\hline Cloud water profile $(<100 u m)$ LT & here & 15 & 17 & 12 & & 4 & 13 & 10 & 8 & 7 & & 5 & 2 & 2 & 2 & 2 & 0 & 0 & 0 & n & 0 & & & \\
\hline Downwelling longwave radiation at Earth's surface & Atmo & 10 & 10 & 9 & 91 & 0 & 9 & 8 & 8 & 10 & & 8 & 8 & 8 & 8 & 7 & 5 & 3 & 3 & 2 & 3 & 3 & 2 & \\
\hline Downwelling solar radiation at TOA & here & 10 & 11 & 10 & & 0 & 9 & 9 & 9 & 10 & & 6 & 6 & 6 & 6 & 6 & 4 & 3 & 3 & 2 & 3 & 3 & 2 & \\
\hline Downwelling SW radiation at Earth's surface & here & 6 & 6 & 5 & 5 & 4 & 4 & 4 & 5 & $\epsilon$ & & 4 & 5 & 5 & 5 & 5 & 4 & 3 & 3 & 2 & 3 & 3 & 2 & \\
\hline Greenhouse gas: $\mathrm{CH} 4$ Total column & ere & 8 & 10 & 8 & 8 & 9 & 8 & 7 & 5 & 4 & & 3 & 1 & 1 & 1 & 1 & 0 & 0 & 0 & 0 & 0 & & & \\
\hline Greenhouse gas: $\mathrm{CO} 2$ total column & ere & 6 & 8 & 8 & 3 & 7 & 7 & 7 & 5 & 3 & & 2 & 0 & 0 & 0 & 0 & 0 & 0 & 0 & n & 0 & j & & \\
\hline Greenhouse Gas: N2O HT profile & here & 3 & 2 & 1 & 1 & 1 & 1 & 1 & 0 & $\mathrm{c}$ & & 0 & 0 & 0 & 0 & 0 & 0 & 0 & 0 & 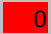 & 0 & j & & \\
\hline Greenhouse Gas: N2O LS profile & here & 2 & 2 & 2 & 2 & 3 & 2 & 2 & 1 & 2 & & 2 & 1 & 1 & 1 & 1 & 0 & 0 & 0 & $\sqrt{3}$ & 0 & j & & \\
\hline e Gas: N2O total colum & here & 2 & 2 & 1 & 1 & 1 & 1 & 1 & 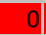 & & & 0 & 0 & 0 & 0 & 0 & 0 & 0 & 0 & 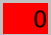 & 0 & & & \\
\hline top of the PBL & here & 2 & 2 & 0 & & 0 & 0 & 0 & 0 & 1 & & 1 & 1 & 1 & 1 & 1 & 1 & 0 & 0 & - & 0 & & & \\
\hline Height of the tropopause & Atmosphere & 9 & 9 & 9 & 9 & 8 & 7 & 4 & 5 & $\epsilon$ & & 6 & J & 5 & 4 & 4 & 2 & 2 & 3 & 2 & 3 & & & \\
\hline Outgoing longwave radiation at TOA & Atmosphere & 27 & 32 & 30 & & & 26 & 21 & 19 & 16 & 1 & 3 & 10 & 11 & 11 & 11 & 8 & 6 & 6 & 4 & 5 & 3 & & \\
\hline Outoging shortwave radiation at TO & tere & 10 & 10 & 9 & 91 & 0 & 10 & 11 & 11 & 10 & & 8 & 7 & 8 & 9 & 9 & 7 & 5 & 3 & 2 & 2 & 1 & 1 & \\
\hline Ozone profile LT & here & 10 & 9 & 8 & 8 & 8 & 6 & 4 & 4 & 4 & & 5 & 3 & 3 & 2 & 2 & 0 & 0 & 0 & & 0 & & & \\
\hline Ozone total column & Atmos & 21 & 25 & 23 & & 3 & 19 & 16 & 17 & 16 & 1 & 4 & 11 & 10 & 9 & 8 & 5 & 2 & 3 & 2 & 3 & & 3 & \\
\hline Precipitation & tere & 2 & 3 & 3 & 3 & 3 & 4 & 5 & 5 & $\epsilon$ & & 5 & 6 & 5 & 5 & 6 & 4 & 3 & 4 & 3 & 4 & 2 & 2 & \\
\hline Precipitation $\mathrm{F}$ & ere & & 2 & 2 & 2 & 2 & 2 & 2 & 2 & 1 & & 1 & 0 & 0 & 0 & 0 & 0 & 0 & 0 & & & & & \\
\hline Precip & re & 35 & 40 & 38 & & 7 & 31 & 26 & 26 & 22 & 22 & 0 & 16 & 16 & 13 & 13 & 10 & 7 & 7 & 5 & 6 & & & \\
\hline Precip & & 1 & 2 & 3 & 3 & & 4 & 5 & 6 & 5 & & 5 & 5 & 6 & 6 & 7 & 6 & 5 & 4 & 3 & 3 & 1 & & \\
\hline Press & re & 1 & 1 & 3 & 3 & 3 & 3 & 3 & 2 & 4 & & 3 & 4 & 6 & 6 & 7 & 5 & 5 & 5 & 4 & 5 & 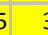 & & \\
\hline y profile $\mathrm{L}$ & Atm & 33 & 38 & 35 & 53 & 5 & 30 & 30 & 29 & 26 & 2 & 3 & 17 & 17 & 14 & 14 & 8 & 4 & 3 & 3 & 3 & 2 & & \\
\hline y profile $\mathrm{HT}$ & Atm & 26 & 29 & 26 & 62 & 5 & 20 & 17 & 15 & 12 & 1 & 0 & 6 & 8 & 7 & 7 & 5 & 4 & 3 & 2 & 2 & 2 & 1 & \\
\hline Specific humidity profile Total & & 4 & 4 & 4 & 4 & 4 & 4 & 2 & 2 & 1 & & 0 & 0 & 0 & 0 & 0 & 0 & 0 & 1 & $\sqrt{2}$ & 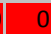 & & & \\
\hline Specific Humidity profile Tro & ere & 28 & 33 & 33 & 33 & & 28 & 25 & 20 & 17 & $7 \quad 1$ & 7 & 11 & 12 & 10 & 11 & 7 & 5 & 3 & 3 & 3 & 1 & & \\
\hline Total solar irradiance (TSI) & Atmosphere & 8 & 12 & 10 & & & 7 & 6 & 6 & 5 & & 4 & 3 & 4 & 5 & 6 & 4 & 3 & 3 & 2 & 2 & 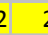 & & \\
\hline Wind profile (horizontal) HT & ere & 14 & 16 & 15 & 5 & & 13 & 12 & 11 & 10 & 1 & 1 & 9 & 7 & 6 & 6 & 4 & 1 & 1 & 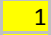 & 1 & 1 & & \\
\hline Wind profile (horizontal) LT & & 9 & 10 & 9 & & & 8 & 8 & 7 & $\epsilon$ & & 7 & 6 & 5 & 5 & 5 & 3 & 1 & 1 & 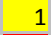 & 1 & & & \\
\hline Wind speed over land surface & Atmosphere & & & & & & & & & & & & 0 & & & 0 & 0 & & & & & & & \\
\hline
\end{tabular}

Table 1. Total number of CEOS space missions (per year) planned over the next 20 years measuring atmospheric parameters relevant to the Energy SBA decision topic, "Identify and quantify the availability of traditional and renewable energy resources". "No planned missions” for a given measurement is highlighted in dark red. " 1 to 5 planned missions” for a given requirement is highlighted in yellow. " 5 or more planned missions" is shown in white. These mission-count classifications and color codes can be used to identify potential mission gaps that may impact the Energy SBA decision topic. 


\begin{tabular}{|c|c|c|c|c|c|c|c|c|c|c|c|c|c|c|c|c|c|c|c|c|c|}
\hline Measurement / Year & Domain & $\begin{array}{l}\infty \\
\stackrel{\circ}{\mathrm{N}}\end{array}$ & 옹 & 웅 & 곡 & 고ํ & $\stackrel{m}{\stackrel{M}{\sim}}$ & 总 & 물 & $\begin{array}{l}0 \\
-1 \\
\stackrel{N}{N}\end{array}$ & 공 & $\begin{array}{l}\infty \\
\stackrel{-}{\circ} \\
\text { N }\end{array}$ & 疋 & 옹 & ్ㅗ & స్్ & స్ํํ & ্ָণ & స̊ & $\stackrel{\text { N }}{\stackrel{N}{N}}$ & స̃ \\
\hline Land cover type & Land & 22 & 21 & 19 & 20 & 21 & 23 & 18 & 18 & 12 & 7 & 8 & 10 & 9 & 7 & 6 & 4 & 3 & 3 & 2 & 1 \\
\hline Land surface imagery & Land & 51 & 55 & 53 & 53 & 54 & 50 & 42 & 41 & 34 & 20 & 21 & 23 & 20 & 13 & 11 & 9 & 7 & 5 & 4 & 3 \\
\hline Land surface temp & Land & 34 & 36 & 35 & 35 & 28 & 26 & 24 & 21 & 19 & 12 & 13 & 12 & 12 & 8 & 5 & 3 & 2 & 2 & 2 & 2 \\
\hline Land surface topography & Land & 20 & 20 & 15 & 17 & 16 & 15 & 10 & 12 & 11 & 7 & 7 & 6 & 5 & 2 & 1 & 1 & 1 & 1 & 0 & 0 \\
\hline Leaf area index (LAI) & Land & 7 & 6 & 5 & 5 & 5 & 4 & 3 & 3 & 3 & 2 & 4 & 5 & 6 & 5 & 5 & 3 & 2 & 2 & 1 & 1 \\
\hline Normalized Difference Vegetation Index(NDVI) & Land & 17 & 18 & 18 & 17 & 18 & 14 & 14 & 15 & 15 & 11 & 13 & 14 & 14 & 10 & 8 & 7 & 5 & 6 & 5 & 4 \\
\hline Snow cover (all-weather) & Land & 4 & 4 & 3 & 3 & 3 & 4 & 3 & 3 & 2 & 1 & 1 & 1 & 1 & 0 & 0 & 0 & 0 & 0 & 0 & 0 \\
\hline Snow cover (ocean) & Land & 28 & 33 & 31 & 28 & 28 & 26 & 24 & 21 & 20 & 14 & 14 & 13 & 14 & 8 & 6 & 4 & 3 & 3 & 2 & 2 \\
\hline Snow water equivalent & Land & 8 & 9 & 7 & 6 & 5 & 5 & 4 & 3 & 3 & 3 & 3 & 2 & 2 & 0 & 0 & 0 & 0 & 0 & 0 & 0 \\
\hline Soil moisture & Land & 20 & 23 & 24 & 24 & 24 & 23 & 21 & 18 & 16 & 12 & 13 & 11 & 12 & 8 & 7 & 5 & 4 & 4 & 1 & 1 \\
\hline Soil type & Land & 3 & 3 & 4 & 4 & 6 & 8 & 8 & 8 & 7 & 5 & 8 & 8 & 8 & 6 & 6 & 4 & 3 & 3 & 1 & 1 \\
\hline Vegetation type & Land & 38 & 36 & 30 & 30 & 33 & 33 & 26 & 27 & 22 & 15 & 16 & 15 & 14 & 10 & 8 & 7 & 5 & 6 & 3 & 3 \\
\hline ocean color & Ocean & 8 & 8 & 8 & 7 & 6 & 6 & 6 & 5 & 5 & 2 & 2 & 1 & 1 & 1 & 0 & 0 & 0 & 0 & 0 & 0 \\
\hline ocean currents & Ocean & 3 & 3 & 3 & 3 & 2 & 3 & 1 & 1 & 2 & 2 & 2 & 1 & 1 & 0 & 0 & 0 & 0 & 0 & 0 & 0 \\
\hline Ocean dynamic topography & Ocean & 10 & 10 & 7 & 8 & 6 & 8 & 7 & 7 & 7 & 5 & 4 & 4 & 4 & 1 & 1 & 1 & 0 & 0 & 0 & 0 \\
\hline Ocean surface salinity & Ocean & 0 & 0 & 1 & 1 & 1 & 1 & 1 & 1 & 0 & 0 & 0 & 0 & 0 & 0 & 0 & 0 & 0 & 0 & 0 & 0 \\
\hline Sea ice concentration & Ocean & 0 & 0 & 1 & 1 & 1 & 1 & 1 & 1 & 0 & 0 & 0 & 0 & 0 & 0 & 0 & 0 & 0 & 0 & 0 & 0 \\
\hline Sea level & Ocean & 6 & 8 & 6 & 6 & 4 & 4 & 1 & 1 & 2 & 1 & 1 & 1 & 1 & 0 & 0 & 0 & 0 & 0 & 0 & 0 \\
\hline Sea surface temperature & Ocean & 32 & 35 & 33 & 34 & 28 & 27 & 26 & 25 & 23 & 17 & 17 & 17 & 18 & 12 & 8 & 7 & 5 & 6 & 4 & 4 \\
\hline Seaice cover & Ocean & 28 & 33 & 32 & 31 & 32 & 28 & 25 & 22 & 19 & 13 & 13 & 10 & 11 & 6 & 4 & 4 & 4 & 4 & 2 & 2 \\
\hline Seaice cover (all-weather) & Ocean & 4 & 4 & 3 & 3 & 3 & 4 & 3 & 3 & 2 & 1 & 1 & 1 & 1 & 0 & 0 & 0 & 0 & 0 & 0 & 0 \\
\hline Seaice sheet topography & Ocean & 3 & 4 & 3 & 4 & 5 & 5 & 4 & 5 & 4 & 3 & 2 & 2 & 2 & 0 & 0 & 0 & 0 & 0 & 0 & 0 \\
\hline Seaice surface temperature & Ocean & 2 & 2 & 4 & 3 & 3 & 4 & 2 & 2 & 2 & 2 & 4 & 5 & 6 & 5 & 5 & 3 & 2 & 2 & 1 & 1 \\
\hline Seaice thickness & Ocean & 19 & 24 & 20 & 22 & 22 & 17 & 14 & 13 & 11 & 8 & 8 & 6 & 5 & 2 & 1 & 1 & 1 & 1 & 0 & 0 \\
\hline Seaice Type & Ocean & 7 & 7 & 7 & 8 & 7 & 9 & 7 & 8 & 7 & 6 & 9 & 9 & 9 & 6 & 6 & 4 & 3 & 3 & 1 & 1 \\
\hline Significant wave height & Ocean & 9 & 9 & 4 & 7 & 6 & 9 & 8 & 9 & 8 & 6 & 7 & 6 & 5 & 3 & 2 & 2 & 1 & 1 & 0 & 0 \\
\hline Wave directional energy frequency spectrum & Ocean & 1 & 1 & 1 & 4 & 4 & 4 & 4 & 4 & 3 & 2 & 3 & 2 & 1 & 1 & 1 & 1 & 1 & 1 & 0 & 0 \\
\hline Wind speed over sea surface (horizontal) & Ocean & 16 & 17 & 17 & 17 & 15 & 13 & 11 & 10 & 8 & 5 & 5 & 4 & 5 & 2 & 2 & 2 & 2 & 2 & 1 & 1 \\
\hline Wind vector over sea surface (horizontal) & Ocean & 10 & 10 & 9 & 9 & 7 & 7 & 5 & 4 & 4 & 3 & 5 & 5 & 6 & 5 & 5 & 3 & 2 & 2 & 1 & 1 \\
\hline Wind vector over surface & Ocean & 0 & 1 & 2 & 2 & 3 & 3 & 3 & 5 & 5 & 4 & 4 & 6 & 6 & 4 & 4 & 3 & 3 & 1 & 0 & 0 \\
\hline
\end{tabular}

Table 2. Total number of CEOS space missions (per year) planned over the next 20 years measuring land and ocean parameters relevant to the Energy SBA decision topic, "Identify and quantify the availability of traditional and renewable energy resources”. "No planned missions” for a given measurement is highlighted in dark red. "1 to 5 planned missions” for a given requirement is highlighted in yellow. " 5 or more planned missions" is shown in white. These mission-count classifications and color codes can be used to identify potential mission gaps that may impact the Energy SBA decision topic.

There are several potential near-term measurement gaps for this Energy SBA decision topic. These are defined as measurements with an average of less than 2 missions per year over the next 10 years. These gaps include (1) Air Pressure over Sea Surface, (2) Chemically active species and Greenhouse Gases (NO,NO2,SO2,N2O), (3) Clouds (drop effective radius, ice profile), (4) Height of the Top of the Planetary Boundary Layer (PBL), (5) Ocean surface salinity, (6) Precipitation profiles (liquid and solid), (7) Sea ice concentration, and (8) Wind speed over land. Additional details on the missions currently addressing these gap areas has been provided to Richard Eckman (CEOS Energy SBA Lead) in a preliminary gap analysis report.

Understanding the potential of solar, wind, geothermal and ocean energy for long term use requires critical space-based measurements in the atmosphere, ocean and land to accurately reflect the current and future state of the Earth. The inability to adequately measure these key parameters will increase the relative uncertainty of decision makers who rely on informational products and models to inform their decisions. 


\subsection{Conclusions}

GEO is leading an international effort to utilize Earth observations and the information derived from these observations to help solve complex global problems such as limited resources in the face of population growth and climate change. The GEO plan envisions major advances over the next ten years accomplished by collaboration and coordination of investments by nations around the world. As explained by Thomas Freidman ${ }^{4}$ in his book "The World is Flat", recent technological advances in communication and the internet have created a new potential for global collaboration that was not available 10 years ago. These advances will stimulate and improve collaboration, but effective systems engineering is still required to guide the implementation of potential solutions.

Designing the GEOSS to meet societal needs is more difficult than designing the GEOSS to meet science community needs. Specifically, this approach requires that the information needed to provide societal benefits be clearly defined and comprehensive. This information is a complex mix of measurements, science knowledge, models, and information products that is best categorized in a framework aligned with societal benefit and the support of critical decisions. This new requirements taxonomy is more complex than the traditional mission planning process for science driven programs. To benefit from the innovation of GEO these complexities demand a systems engineering approach for effective and efficient implementation.

The SEO analysis of a single decision topic within the Energy SBA utilizes this new framework or taxonomy for organizing requirements, assessing the current gaps in space-based measurements and missions, and assessing the impact of the current and planned space-based missions. It was determined that several potential near-term measurement gaps exist. Understanding the quantity and availability of traditional and renewable energy resources requires the measurement of critical atmospheric, land and ocean variables in the future. Though this may appear obvious to scientists, it is now further supported by societal benefit needs.

\section{REFERENCES}

[1] Global Earth Observation System of Systems (GEOSS), "10-Year Implementation Plan Reference Document", Group on Earth Observations - GEO 1000R, (2005).

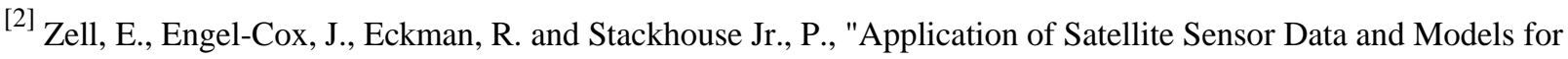
Energy Management,", IEEE J. Selected Topics in Applied Earth Observations and Remote Sensing, (2008).

${ }^{[3]}$ Eckman, R., personal communication, (2008).

${ }^{[4]}$ Friedman, T., [The World is Flat], Picador/Farrar, Stratus and Giroux Publishers, New York, (2005). 